\title{
The role of direct current potentials in assessment of energy metabolism pattern in surgical patients
}

\author{
I Zabolotskikh*, T Musaeva, K Zybin \\ From ESICM LIVES 2015 \\ Berlin, Germany. 3-7 October 2015
}

\section{Introduction}

Correction of metabolic disorders is an obligatory component in treatment of the majority of the pathological processes, allowing to avoid deterioration of a condition of the patient and accordingly to reduce time of stay in a hospital.

\section{Objectives}

Develop a mode of noninvasive, informative and accessible in practical application the express-test of energy metabolism pattern

\section{Methods}

The study was performed on 183 patients underwent abdominal surgery (duration 6-9 hours). Were assessed central hemodynamics, gas exchange, temperature and nutrition state for the nutrition support. The nutritional support has based on monitored nutritional status. Depending on energy metabolism pattern defined by biochemical tests, patients were divided on 4 groups: group 1 - enzymic energy metabolism pattern, group 2 - hypoxic energy metabolism pattern, group 3 - substrate energy metabolism pattern, group 4 included the patients with hypermetabolic energy metabolism pattern. The concurrent registration of direct-current potential (DCP) and number of superslow oscillations (SSO) was made in a forehead-palm lead.

\section{Results}

The enzymic energy metabolism pattern correspond with zero to $3 \mathrm{SSO}$ and DCP value more than $-10 \mathrm{mV}$; the hypoxic energy metabolism pattern correspond with more than $10 \mathrm{SSO}$ and DCP value more than $-15 \mathrm{mV}$; the substrate energy metabolism pattern correspond with more than 10 SSO and "optimal" DCP value of -15 to $-35 \mathrm{mV}$;

Kuban Medical University, Krasnodar, Russian Federation the hypermetabolic energy metabolism pattern correspond with more than $18 \mathrm{SSO}$ and DCP value less than $-35 \mathrm{mV}$; optimal (normal) energy metabolism pattern correspond with 4 to $9 \mathrm{SSO}$ and DCP value of -15 to $-35 \mathrm{mV}$.

\section{Conclusions}

The DCP monitoring allows to determine the kind of energy metabolism pattern on the basis of number of superslow oscillations of direct current potential during ten minutes and background values of direct-current potential.

Published: 1 October 2015

\section{Reference}

1. Zabolotskikh IB, Musaeva TS, Grigoriev SV: The metabolic responses during postanesthesia recovery after prolonged abdominal surgery under total intravenous anesthesia: A-808. European Journal of Anaesthesiology 2006, 23(Supplement 37):209.

doi:10.1186/2197-425X-3-S1-A577

Cite this article as: Zabolotskikh et al:: The role of direct current potentials in assessment of energy metabolism pattern in surgical patients. Intensive Care Medicine Experimental 2015 3(Suppl 1):A577.

Submit your manuscript to a SpringerOpen ${ }^{\circ}$ journal and benefit from:

- Convenient online submission

- Rigorous peer review

- Immediate publication on acceptance

- Open access: articles freely available online

- High visibility within the field

- Retaining the copyright to your article

Submit your next manuscript at $>$ springeropen.com

\section{SpringerOpen ${ }^{\circ}$}

(c) 2015 Zabolotskikh et al.; This is an Open Access article distributed under the terms of the Creative Commons Attribution License (http://creativecommons.org/licenses/by/4.0), which permits unrestricted use, distribution, and reproduction in any medium, provided the original work is properly cited. 